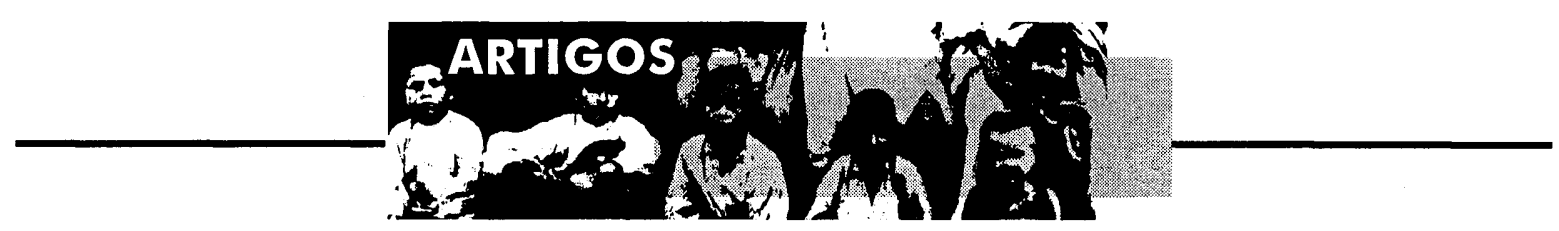

\title{
Políticas Científicas e Tecnológicas para a Saúde Coletiva
}

\author{
Hillegonda Maria Dutilh Novaes ${ }^{1}$ \\ Ricardo Lafetá Novaes ${ }^{1}$
}

Resumo: Este artigo apresenta a história e os fundamentos da ciência e tecnologia em saúde coletiva, no interior do desenvolvimento da ciência e tecnologia nacionais. Discute a lógica das políticas científicas e sua apropriação pelo campo da saúde, enquanto complexo sistema de interações entre a comunidade acadêmica, entidades financiadoras e associação representativa da área de conhecimento.

O texto recupera o lugar e o espaço da produção científica, do papel do fomento e da avaliação, e termina apontando as tendências e desafios que a saúde coletiva tem pela frente, na década de 90 , enquanto campo de conhecimento.

Palavras-chave: Ciência e Tecnologia; Saúde Coletiva; Política Científica; Campo Intelectual

Summary: The paper presents the history and grounds of Science \& Technology development in the realm of Public Health, and their relationships with Brazilian scientific milieu. The authors discuss the intrinsic logic of scientific policies and the way they are incorporated by the field of health sciences as a complex system of interaction of the academic scene with funding sources and the Brazilian professional association devoted to Public Health (ABRASCO). The paper addresses the scope of scientific knowledge in Brazilian Public Health, and the role of funding agencies and their strategies of evaluation. Finally, recent trends and current dilemmas of Public Health as a scientific endeavor are analyzed.

Keywords: Science \& Technology; Public Health; Scientific Policy; Intellectual Realm

\footnotetext{
' Departamento de Medicina Preventiva, Faculdade de Medicina, Universidade de São Paulo, São Paulo, SP.
} 


\section{Considerações Gerais}

\section{a) Estado, Ciência e Técnica}

A idéia de que as condições de saúde das populações relacionam-se com as condições de vida que thes são oferecidas não constitui exatamente uma novidade. Diferentemente concebida, segundo os diversos momentos da história nos quais pode ser identificada, assenta-se, no geral, na concepção de que más condiçôes de existência "geram" sofridas situaçôes de vivência. As novidades situam-se, é claro, no plano da compreensão dos processos que se exprimem nestas relações "causais" e, principalmente, nas formas construídas como soluções desejadas. As primeiras referem-se à ciência, preliminarmente pensada como consciência do mundo, e, as segundas, a ações que, de uma maneira ou outra, derivam do saber que nos permite operar sobre este mundo. Ciência e técnica, saber e fazer, são termos correspondentes que caracterizam o que é propriamente humano.

Não sendo nova a idéia, trata-se aqui de ressaltar a novidade do agir. É somente sob o capitalismo, com a revolução industrial consolidando sua hegemonia enquanto modo de produzir, que a população e suas condições de saúde são tomadas como questão de Estado. A Saúde Pública, todavia e em seus primórdios, não é mais do que uma ação estatal que corresponde a interesses bem especificados, quais sejam os relativos à higidez da força de trabalho. Esta história já é bem conhecida e se é aqui relembrada o é, simplesmente, para marcar a diferença com relação a posições posteriores que nos dizem respeito mais de perto. São elas as conquistas democráticas construídas ao longo de século e meio de lutas, traduzidas pela noção de cidadania. Assim, o que se apresentava como uma necessidade do interesse dominante, constrói-se, hoje, como exigência da consciência. Ou seja, a ação do Estado deve ser, também, orientada para benefício da maioria.
Tomado como instrumento potencialmente libertador do homem de sua condição desfavorável, o Estado deve proporcionar um desenvolvimento da sociedade que, pelo menos, diminua as diferenças gritantes existentes entre estratos da população. Regulando os processos econômicos e sociais através de suas políticas, deveria ele, enquanto representante de um interesse geral, prover o maior bem estar social possivel. É a partir de tal concepção que se constróem noções segundo as quais a saúde é "o completo bem estar físico, mental e social", de que ela é "direito de todos" e "dever do Estado", tal qual se encontra consagrada em nossa atual Constituição e, até mesmo, de que o ano 2000 será a data de realização do desejo de que todos serão sadios.

As formas de construção de um tal modelo são duas: política e técnica, nesta ordem de precedência. É por intermédio da primeira que se logrará armar o equipamento indispensável à montagem do cenário no qual a peça se desenrolará, segundo um roteiro derivado de princípios e valores, tomados e/ ou vistos como universais: liberdade, igualdade e fraternidade. À segunda, pertence o modus operandi, ou seja, como fazer, no concreto, aquilo que feito está na abstração ideal. A técnica humana, engenho e arte, é pura invenção e, como tal, produto de uma consciência sempre racional. Quer dizer, o fazer humano depende, sempre e necessariamente, de um saber, ao contrário do que se dá com a mais laboriosa das abelhas.

A questão, bem se vê, é a do estatuto do saber. Se todos eles, coexistindo em uma determinada época, se eqüivalessem, nenhuma mudança seria possível e o mundo, sempre o mesmo, só se alteraria pelas leis físicoquímicas (com sua componente biológica específica), através de uma "história" dita "evolutiva e natural". Como o homem age sobre o mundo, modificando-o, suas técnicas reportam-se a saberes diferenciados, sendo uns superiores a outros. Esta distinção hie- 
rarquizada decorre da simples ação da razão, aqui tomada na sua mais primária acepção, qual seja, a da "argumentação irrefutável". A razão é a afirmação para a qual, convencido ou não, não encontro proposição alternativa que a negue ou a complemente. Em geral, a este saber superior, dá-se o nome de "ciência".

Não havendo aqui nenhuma intenção de se retomar qualquer "discussão epistemológica", parece importante ressaltar as relações entre ciência e tecnologia, assim como as que com elas estabelecem as instâncias políticas e sociais. Um primeiro aspecto refere-se ao valor que se tem dado ao conhecimento científico, notadamente quando o pensamento se dirige à "técnica", vale dizer, modo de fazer que necessariamente significa a resolução de algum problema, premente ou não. Assim, e de um lado, cria-se o mito de que só a ciência pode "validar" as técnicas e, de outro, e por conseqüiência, que os problemas só podem ter soluções se elas forem "científicas".

Uma pergunta parece ser pertinente: para que serve o saber ? É certamente utilitarista esta questão mas, sem dúvida, é sempre da utilidade que se trata quando se considera o ser vivo. Uma primeira resposta pode, claramente, ser admitida: o saber serve ao prazer. O hedonismo aí identificável não viria mais do que corroborar um dos pilares do pensamento moderno que o transformou em "princípio explicativo" da "essência humana", mas também o "amor à verdade" cultivado desde os primórdios da civilização ocidental. Mas também, e novamente com grande utilidade, o saber serve para compreender melhor o mundo e sobre ele interferir, para nosso prazer.

A ciência é, assim, não mais do que o novo produzido pela razão humana, conferindo sentido ao mundo por ela percebido. Se tal novidade não encerra nenhum "valor de uso", das duas uma: ou a demanda deriva de uma outra instância, quer dizer, a resposta obtida pertence a uma esfera diversa daquela na qual a pergunta foi formulada, ou o seu alcance e utilidade, quem sabe, somente "um dia" serão visualizados. Em outros termos, se o novo é sempre uma resposta, o seu caráter não é necessariamente "prático", ou seja, resolutivo do estar no mundo. Se o novo é sempre uma resposta ao pensamento, pode ela não se referir ao problema concreto com o qual me defronto, pode não ser a soluçào procurada, dado que, como já se apontou, minha demanda se origina em instâncias da vida cujo fundamento não é propriamente uma prática do intelecto que se quer científica. Assim, se a ciência não pode ser a solução universal, também não se constitui em instrumental único da ação do homem sobre o mundo. Donde, se técnicas dela derivam, também em outros saberes elas encontram origem e consistência. O que chamamos, por exemplo, "intuição", tem se revelado em diversos momentos como fonte de soluçōes engenhosas, mesmo porque, às vezes, surgem contra a racionalidade dominante, tida como superior e, portanto, científica.

Todavia, quando se considera a historicidade dos acontecimentos, identifica-se uma tendência da era moderna no sentido de construir seus "modos de fazer" (técnica) de forma cada vez mais aproximada do saber racional que, por sua superioridade, se quer científico. Superioridade argumentativa, já se viu, mas também cada vez mais assentada nas noçōes de previsibilidade e de eficácia. A primeira deixou de ser função dos oráculos, resultando hoje, e essencialmente, de "bases de dados" sobre as quais cálculos podem ser realizados. A segunda, não mais ação de demiurgos, resulta de uma outra "astúcia" da razão que é o aprimoramento do projeto e, principalmente, a avaliação do resultado, ou seja, a comparação do obtido em relação ao esperado. A ação do homem sobre a nature$\mathrm{za}$, na qual ele próprio se inclui, tornando-se cada vez mais potente, busca ser cada vez mais eficiente (maior resultado com o mínimo de desgaste) com vista a uma máxima efetividade (eficácia em condições reais). 
Com que resultados ? Nem sempre os esperados, seja em decorrência de insuficiências dos próprios saberes e técnicas, seja, como é o mais comum, pela natureza da distribuição social dos benefícios produzidos pela ciência e tecnologia. Donde, novamente, e em função do "interesse geral", a retomada da cena na qual o Estado ocupa a posição central.

\section{b) Políticas científicas e tecnológicas}

Isabelle Stengers (1993) conta que a idéia de subordinar a racionalidade da produção científica a objetivos que lhes são exteriores ganhou corpo, nas sociedades da Europa ocidental, a partir do II Congresso Internacional da História da Ciência e da Tecnologia, realizado em Londres, em 1931. A partir de entusiasmados posicionamentos de Bukarin, jovens marxistas ingleses como Needham e Bernal publicam textos defendendo uma função social da ciência na qual produção científica e interesses sociais e econômicos são solidários de direito e de fato. Visão que, ainda que combatida, acaba sendo, após a Segunda Grande Guerra, incorporada ao ideário dos defensores das sociedades de "bem-estar social". Bem se vê que, deste então, tal debate continua vivo entre historiadores, sociólogos e filósofos da ciência. Trata-se de melhor diferenciar os determinantes "internos" e "externos" da produção científica, tendo em vista o estabelecimento de "políticas científicas", cada vez mais legitimadas como instrumentos de intervenção sobre o social.

Outros debates podem ser identificados, como o que opõe os partidários da "tecnociência" àqueles que, advogando um "humanismo", vêem uma subordinação do ser humano às técnicas e aos saberes, ou ainda, ciência e gênero, ciência e raça e ciência e condições sócio-econômicas. Todavia, um ponto que mais recentemente tem causado intensa mobilização dos cientistas, principal- mente aqueles que estão envolvidos com as chamadas "ciências duras", refere-se a concepções "relativistas", segundo as quais a atividade científica é uma prática social essencialmente igual a todas as outras. É evidente que os que discordam o dizem por entenderem que a racionalidade científica se constrói a partir de critérios e regras específicos, como já se fez alusão anteriormente. De toda forma, sejam quais forem as abordagens e posicionamentos sobre a questão, o que interessa ressaltar aqui são as intervenções estatais sob a forma de políticas científicas, às vezes resultantes de debates como os acima referidos.

Assim, e ainda em um plano mais geral, considera-se o período que vai do pós-guerra até o final dos anos 60 como o da "idade de ouro" das políticas científicas. Os países capitalistas, especialmente aqueles que saíram vitoriosos do conflito, criaram grandes projetos temáticos e instituiçôes de pesquisas capazes de realizá-los, principalmente nas áreas da física e da química. No plano tecnológico, o processo industrial tratou de incorporar as inovações resultantes do esforço de guerra como elementos de desenvolvimento de suas forças produtivas e, por conseqüência, de sua produtividade. Isso porque, segundo afirma Rosenberg, no seu artigo, "Como os países desenvolvidos ficaram ricos" (1994, p. 134): "no conjunto de forças que interagem para a construção do sistema industrial, a aplicação do conhecimento e do método científico a um número cada vez maior de atividades produtivas se constitui em um elemento proeminente".

As duas décadas seguintes testemunharam diversas crises econômicas, que também resultaram em recomposições e surgimento de novas forças industriais e financeiras que, dada a tendência de aumento da competitividade, passaram a se apoiar em novos paradigmas tecnológicos como, por exemplo, a microeletrônica (Baltar, 1993). Período no qual se pode identificar um redirecionamento das políticas de $C$ \& $T$, que passam a visar soluções para os problemas nacionais. 
Para os anos 90 pode-se dizer que, se de um lado, sinalizam para uma internacionalização e globalização cada vez maiores das atividades econômicas, financeiras e também de pesquisa e desenvolvimento, por outro, pretendem dar conta de questões mais específicas, sem que haja um caráter de "salvação nacional" (OECD, 1992; Chesnais, 1991). Atualmente, considera-se que as políticas (policies) em C \& T devem enfrentar algumas questões básicas para que sejam efetivas: equilíbrio entre recursos públicos e privados, reconhecimento das novas demandas sociais, integração entre as dimensões nacionais e internacionais e a superação de uma certa rigidez dos sistemas de Pesquisa e Desenvolvimento ( $P \& D)$, tanto no que se refere aos contornos das áreas de conhecimento, quanto à formação e disponibilidade de recursos humanos (OECD, 1992). Também têm sido tomadas em consideração as pressôes da chamada "opinião pública" que, ao externar uma atitude geral favorável à C \& T, manifesta preocupações relativas aos impactos ambientais e às questões éticas envolvidas na difusão de algumas tecnologias.

Apesar de problemas comuns, os países desenvolvidos apresentam trajetórias diversas no enfrentamento das questões de C \& T, em função de suas condições sócio-econômicas gerais, suas estruturas educacionais e de pesquisa, a posição e formas de atuações de seus governos, assim como de suas características culturais. No que diz respeito especificamente à $\mathrm{P} \& \mathrm{D}$, trata-se de uma das mais concentradas atividades do planeta: apenas 5 países (Estados Unidos da América, Japão, Alemanha, França e Reino Unido) concentram 90\% dos recursos investidos (Hatzichronoglou, 1991). Para os anos 90, os estudos indicam que o processo de internacionalização se dá de maneira mais acentuada entre os países com forte atividade de $\mathrm{C} \& \mathrm{~T}$, observando-se uma tendência de participação decrescente da África e da América Latina neste panorama. É que, também nestas atividades, são necessárias certas pré-condições. O "mérito científico" não parece ser fator suficiente, ainda que necessário. "Em numerosos casos, a construção institucional acontece e os recursos humanos e financeiros, ainda que insuficientes, não são desprezíveis. Mas, o acúmulo de recursos não leva automaticamente a uma atividade produtiva. Outros fatores tais como as condiçōes para a prática da pesquisa, a profissionalização dos pesquisadores e a emergência de comunidades científicas nacionais socialmente legítimas, são decisivos. [A par disso, mesmo com] a institucionalização da pesquisa, esta não implica necessariamente na sua internacionalização, pois a produção científica local enfrenta dificuldades em ser reconhecida pelas bases de dados internacionais." (Gaillard, 1991).

No processo de elaboração de políticas científicas, todos os países desenvolvem, ainda que com características diversas, complexos sistemas de interação entre comissões científicas acadêmicas, entidades financiadoras de pesquisas e sociedades científicas de diversas áreas do conhecimento. Em geral, os membros destas comissões são escolhidos através de mecanismos mais ou menos representativos dos seguimentos interessados, sendo alguns indicados por instâncias governamentais em consonância com as esferas responsáveis pelas diretrizes políticas e econômicas mais gerais.

Quanto às tecnologias propriamente ditas definições de políticas e prioridades constituem-se, em geral, em processos complexos e às vezes contraditórios, dado que envolvem, além das instâncias já mencionadas, interesses industriais e comerciais, variáveis segundo as diversas conjunturas. Neste contexto, considera-se que, quando na definição de prioridades a "comunidade científica" tem um papel de maior relevância, tendem as definições a serem mais "conservadoras", no sentido da manutenção de um determinado status quo. Quer dizer que se ressalta o conhecimento em marcha e os objetos a ele referentes o que, se garante a continuidade 
das atividades em curso, obstaculiza redefinições eventualmente necessárias. Por outro lado, propostas que ignoram a dinâmica própria da atividade científica, que não estruturam de forma sólida suas alianças, que não contam com infra-estrutura própria e nem com um patamar adequado de recursos, acabam por se revelar inviáveis (OECD, 1991).

Avaliar políticas, através da comparação de resultados com o que foi declinado, é um processo complexo, principalmente por ser altamente controverso. Se o objetivo maior de toda e qualquer política é a promoção do "bem-estar" social, a verificação de um tal desiderato com relação às políticas de ciência e tecnologia não pode ser imediata. Tratando-se de "atividade-meio" por referência àqueles objetivos, a atividade científica só pode ser aferida por critérios que considerem a sua própria finalidade, qual seja, novos saberes e fazeres. Resulta isso na crescente importância da divulgação das atividades científicas e técnicas, traduzida em publicações cada vez mais especializadas que buscam a marca maior da credibilidade. De certa forma, a publicação dos trabalhos científicos confunde-se com o próprio produto da atividade científica e a sua avaliação ("cienciometria") assenta-se fortemente em uma medição das publicações ("bibliometria") através de uma quantificação feita, preferencialmente, em revistas internacionais consideradas "verdadeiramente científicas".

Nào se trata de negar a importância das publicações para a atividade científica pois, ao promoverem a circulação de idéias e debates, constituem-se em importante instrumento contra uma tendência de privatização do conhecimento, principalmente no que se refere àquele produzido por pesquisas sustentadas pelo interesse industrial. Todavia, o que deve ser questionado é o seu uso como instrumento único de quantificação e qualificação da atividade científica, e até mesmo de definição de produto final das ciência. Questão polêmica (Cassen, 1991; OECD, 1991), mas que não será aqui desdobrada.

\section{Políticas de C \& T e Saúde Coletiva}

No contexto das tendências acima referidas, tornou-se possível a formulação do seguinte diagnóstico: o desenvolvimento industrial dos países periféricos, ao tomar como paradigma o modelo de desenvolvimento capitalista central levou, necessariamente, à importação de tecnologia que, considerado o processo de trabalho, resultou em uma ruptura entre o progresso cultural e o progresso técnico. Significa, no fundamental, uma exclusão social e cultural de quem realmente age no processo produtivo. (MCT, FINEP \& $\mathrm{CNPq}, 1985)$. As soluções não estavam - $\mathrm{e}$ não estão - evidentemente dadas, mas implicam em uma revisão da política de ciência e tecnologia implementada pelo Estado brasileiro, considerada a enorme "dívida social" existente, assim como necessidades mais prementes da população brasileira.

Como se sabe, uma primeira tentativa de se criar uma instituição orientadora de uma política de ciência e tecnologia foi realizada em 1931, pela Academia Brasileira de Ciências. Só em 1949, o Presidente Eurico Gaspar Dutra, diante de uma pretensão das potências nucleares de então de que as reservas de minério radioativo só deveriam ser por elas utilizadas, propôs ao Congresso Nacional a criação do Conselho Nacional de Pesquisa CNPq. A lei de 1951 que o institui confere-lhe duas funções: a promoção do desenvolvimento científico e tecnológico do país e o controle do aproveitamento da energia nuclear.

Além da criação da CAPES, ainda em 1951 e por iniciativa de Anísio Teixeira (visando à formação de recursos humanos para o ensino superior e a pesquisa), funda-se um banco nacional cuja finalidade encontrava-se expressa no próprio nome, qual seja, o Desenvolvimento Econômico -- BNDE. É neste espaço e por iniciativa de José Pelúcio Ferreira - motivado por preocupaçōes relativas à engenharia siderúrgica - que, em 1964, instituiu-se um Fundo Nacional de Desenvolvimento Téc- 
nico-Científico - FUNTEC. Aqui, um objetivo marcante teria sido o de despertar o interesse da empresa nacional para o desenvolvimento de atividades de pesquisa e desenvolvimento.

A partir de 1971, a FINEP Financiadora de Estudos e Projetos - , passa a ser a secretaria executiva do FNDCT - Fundo Nacional de Desenvolvimento Científico e Tecnológico - vindo a se tornar uma agência de fomento à $\mathrm{C} \& \mathrm{~T}$ e um dos atores de importantes iniciativas como, por exemplo, a criação da COPPE. É neste contexto que o I PND (1972-1974) faz referência a uma política tecnológica, visando acelerar a transferência de tecnologia do exterior para o país, assim como esforços no sentido de uma elaboração própria de tecnologia. Implanta-se, em 1972, o Sistema Nacional de Desenvolvimento Científico e Tecnológico - SNDCT - , que teria a finalidade de coordenar as ações das agências (CNPq, CAPES, FINEP, "órgãos setoriais" e "órgãos seccionais" de Ministérios EMBRAPA, SUDEPE, EMATER, NUCLE-BRÁS, CNEN, entre outros) e de seus usuários.

De 1973 a 1985, foram elaborados três Planos Básicos de Desenvolvimento Científico e Tecnológico - PBDCT - visando estabelecer condiçôes institucionais para um planejamento em C \& T. Seus objetivos básicos eram a construção de uma estrutura de pesquisa e a capacitaçào de recursos humanos, fortalecimento da empresa nacional no que diz respeito à tecnologia para, finalmente, lograr-se uma relativa independência tecnológica em relação a países dela produtores. Entre a intenção e o gesto, naturalmente, há alguma distância. Se a década de '70 viu crescer os recursos destinados à $\mathrm{C} \& \mathrm{~T}$, entre 1979 e 1984 a participação conjunta do CNPq, CAPES e FINEP caiu de 1,16\% para 0,58 \% do orçamento da União. O FNDCT, que recebia cerca de $1 / 3$ dos recursos do orçamento da União para ciência e tecnologia em 1979, foi contemplado com $6,0 \%$ do orçamento realizado em 1984. De outro lado, as agências existentes, em que pese as diretrizes formais de articulação e planejamento, reforçaram suas "vocações", seguindo seus propósitos originais: formação de pessoal e fomento à pesquisa através de bolsas de estudos e auxílio pesquisa (CNPq), aperfeiçoamento de recursos humanos para as universidades (CAPES) e financiamento de projetos institucionais, não individuais (FINEP). O "sistema" conta ainda com a participação de instâncias ligadas à $\mathrm{C} \& \mathrm{~T}$ em alguns Ministérios e em empresas estatais que, no geral, desenvolvem suas atividades em função de seus interesses e necessidades relativas à produção. Em relação aos estados federados, destaca-se a FAPESP no Estado de São Paulo e, mais recentemente, iniciativas semelhantes no Rio de Janeiro, Rio Grande do Sul e Minas Gerais, como mecanismos de financiamento de ciência e tecnologia.

Uma avaliação primeira da "política" de C \& T permite identificar certas tensões, derivadas dos interesses e posicionamentos dos atores presentes no processo. Em relatório apresentado ao Ministério de Ciência e Tecnologia pelas sociedades científicas, intitulado "Ciência e Tecnologia na Nova República: Análise e Perspectivas", lê-se que "em uma avaliação de conjunto, a organização desenvolvida nos últimos anos deve ser aperfeiçoada, mas sem mudanças drásticas, preservandose o papel das diferentes agências e seu caráter pluralístico. As dificuldades atuais resultam mais da imperícia e de gastos excessivos em administração, de mudanças freqüentes de orientação e de recursos escassos e irregulares, do que das inadequações do modelo. Muitos do problemas pelos quais este tem passado se prendem à orientação tecnocrática de algumas Direçōes, mais preocupadas em 'programar', 'planejar', 'avaliar', 'administrar', 'acompanhar' e 'coordenar' a atividade científica do que em promover o seu desenvolvimento". A ciência deve, no limite, 'correr livre e solta.'" (MCT, FINEP/CNPq, 1985, p. 5). O problema restringe-se a recursos limitados e à sua má gerência. 
No entanto, e já se viu anteriormente, toda e qualquer política persegue uma finalidade. Assim, também, uma política de ciência e tecnologia. Ciência e tecnologia vistas, em geral, como "atividade meio": saber e fazer para o desenvolvimento econômico, para a independência nacional para, finalmente, um desenvolvimento social que represente o fim das injustiças e desigualdades. Teleologicamente pensada, a atividade científica deve ser planejada, administrada, acompanhada e avaliada. Inclusive por uma exigência fundamental de ordem material que é aquela relativa aos recursos. De que forma e por quem tais funções serão exercidas ?

Em princípio por quem paga. Melhor dizendo, por quem gerencia recursos que são, ou deveriam ser, de todos, e para os quais, por definição, o melhor uso deve ser buscado. São as agências financiadoras que, através de mecanismos nem sempre semelhantes, decidem pelo apoio ou não ao projeto, com base, em princípio, em seu conteúdo. O mérito da proposição pode ser avaliado, evidentemente, segundo diversas perspectivas. A primeira, parece claro, refere-se à sua consistência científica. Uma segunda, à sua pertinência com relação à sua contribuição científica, propriamente dita, e, ainda, por referência ao que poderia ser entendido como "utilidade social". Se são critérios genéricos para a atividade de investigação científica, para o campo da Saúde Coletiva têm eles aparecido como quase uma exigência.

É, também, com estas motivações que, ao lado, por exemplo, da política já assentada de apoio a projetos individuais implementadas pelo CNPq, iniciativas pioneiras buscarão orientar a atividade de pesquisa com finalidades mais especificamente sociais. A FINEP surge como primeiro instrumento desta "nova política de C \& T em Saúde Coletiva". Dois objetivos maiores podem ser aí ressaltados: a criação e consolidação de grupos de pesquisa, precisão de objeto de estudos e definiçòes de linhas de investigação. Assim, entre
1975 e 1978, a FINEP, no contexto do soerguimento da FIOCRUZ, e inaugurando uma política de apoio institucional, destina substanciais recursos ao PESES/PEPPE e ao Instituto de Medicina Social da Universidade Estadual do Rio de Janeiro (UERJ). A intenção era de que, formados, os grupos seriam absorvidos pelas instituições, o que se verificou com relativo sucesso.

Este é um contexto propício a iniciativas político-acadêmicas, como aquelas que resultaram na criação, em 1979, da Associação Brasileira de Pós-graduação em Saúde Coletiva - ABRASCO. Ampliando o espaço de atuação política do então "movimento sanitário", que se inaugura com o CEBES - Centro Brasileiro de Estudos de Saúde —, em 1976, a nova associação busca congregar as Faculdades e Escolas de Saúde Pública, Departamentos de Medicina Preventiva e/ou Social, além de Institutos de Pesquisa pertinentes, em torno de um projeto acadêmico-científico voltado para a consolidação do campo da Saúde Coletiva como área de conhecimento científico. Buscando afirmar sua especificidade na construção de explicações mais amplas do processo saúde-doença, a Saúde Coletiva implementa a aproximação de disciplinas que tinham já como seus objetos as relações humanas e sociais, tais como a antropologia, a sociologia e a psicologia, entre outras, apartando-se, de modos e intensidades variadas, das tradicionais áreas de cunho mais biológico. O projeto, bem se vê, quer melhor fundamentar as decisões necessárias à realização de mudanças nas condições de vida e saúde da população brasileira.

Também em decorrência dessa nova iniciativa, no momento seguinte (1978-1979), e ainda com marcante presença da FINEP, busca-se ampliar a base institucional, incluindo grupos cle pesquisa em fase de formação com apoio daqueles já consolidados, através de um mecanismo de "coordenação horizontal", que integraria os projetos de investigação. Além deste aspecto fundamental, a expansão 
do fomento traduziu-se na inclusão de outras áreas do conhecimento, notadamente das ciências sociais. A estratégia revelou-se limitada dado que, e principalmente, os recursos foram fortemente concentrados em poucas instituições. Talvez pela incapacidade dos "grupos emergentes", 60\% dos recursos foram alocados no Instituto de Medicina Social da UERJ e no Departamento de Ciências Sociais da PUC/RJ. Lê-se no Documento Preliminar de Avaliação do Programa de Saúde Coletiva FINEP/CNPq que: "a 'coordenação horizontal' nunca se efetivou, os projetos se desenvolveram de forma isolada e o apoio à PUC não teve como conseqüência a consolidação de linhas de pesquisa em saúde." (Pellegrini, Nicoletti et al., 1986, p. 46)

O primeiro Programa de Saúde Coletiva (1983) resulta, naquilo que lhe é fundamental, no esforço de técnicos da FINEP em delinear e efetivar uma política de C \& $\mathrm{T}$ em saúde (Szklo, 1988). Tendo como meta a expansão e consolidação da capacidade de pesquisa da área de Saúde Coletiva, inova na concepção gerencial ao buscar articular as agências financiadoras com atuação na área tais como a própria FINEP, o CNPq, o MEC/ CAPES, o Ministério da Saúde e a OPS. Além de uma coordenação compartilhada, isto é, composta por representantes das diversas agências, pela primeira vez uma associação de corte científico tem presença definida no processo decisório. À ABRASCO caberia a assessoria de grupos em fase de implantação, além de organizar e coordenar as atividades de avaliação e acompanhamento do programa.

Em 1984, realizou-se a I Reunião de Avaliação do Programa de Saúde Coletiva FINEP/ CNPq cujos objetivos foram, conforme o "Documento Preliminar" já citado, encontrar respostas para os seguintes aspectos: "necessidade de otimização dos recursos existentes, num contexto onde se tornam prioritárias as demandas pela produção de conhecimentos voltados para a superaçāo dos problemas vividos pelo setor e onde se torna fundamental a utilização da experiência acumulada no manejo de instrumentos de planejamento científico; as demandas que se delineiam para o processo de planejamento da Política de Ciência e Tecnologia em futuro próximo e a possibilidade de participaçāo de forma organizada dos pesquisadores da área de saúde coletiva neste processo, através da ABRASCO." (Pellegrini, Nicoletti et al., 1986, p. 41). Racionalizar recursos e participar em decisões, eis a questão.

Deparando-se com uma grande diversidade de projetos, de referências teóricas e de metodologia de pesquisa, verifica-se ainda que os projetos analisados eram de implantação recente e que "são evidentes os esforços dos pesquisadores para a superação das dificuldades enfrentadas. Sem dúvida, a problemática analisada enfrenta a própria situação de pioneirismo de algumas áreas temáticas, em especial aquelas voltadas para a análise da determinação social do processo saúde/doença e para a análise da tecnologia em saúde." (FINEP/CNPq, 1986, p. 74). Entre as recomendações finais da Reuniào, parece significativa aquela que propõe o desenvolvimento de mecanismos de integração entre as diversas áreas, "de modo a superar as dificuldades verificadas na produção do conhecimento". Ressalta-se este ponto no sentido de apontar dificuldades na própria definição do objeto de um campo, ele próprio em definição, exigindo alguma tolerância dos juízos sobre ele formulados.

Todavia, já em 1987, uma análise do programa contido nas justificativas que fundamentaram a proposição do II PSC, apontava que, em decorrência das dimensões da infraestrutura de pesquisa existente no campo da saúde coletiva e do grau de maturidade de sua produção científica, tornava-se necessária uma "reorientação da ênfase nas políticas de seu desenvolvimento científico". Um primeiro ponto refere-se à necessidade de integração entre a produção e a utilização do conhecimento na área de saúde. De certa forma, o que aqui está em questão é, de um lado, a 
própria "utilidacle social" daquilo que a sociedade produz através de seus aparatos técnico-científicos e, de outro, a admissão da existência de um conhecimento utilizável. Neste sentido, a Saúde Coletiva "deve assumir o desafio de contribuir para o estabelecimento de políticas em áreas essenciais para o setor saúde, inclusive as chamadas de ponta como biotecnologia, química fina, informática, microeletrônica e outras". Para isso, é essencial que se explicite uma articulação entre o social e o biológico, considerados os níveis de investigação científica e tecnológica. Assim, "as linhas prioritárias de investigação devem abranger todo o espectro de atuação da saúde coletiva, desde seus limites mais próximos à investigação puramente clínica e biológica, principalmente no campo da epidemiologia, bem como próximos aos limites da área de administração e planejamento, através dos estudos de avaliação de programa, bem como atingindo com clareza o campo social e de políticas em saúde, limitando-se com os estudos puramente sociológicos e/ou políticos." (FINEP, 1987).

Como bem se vê, trata-se de um campo de máxima amplitude, cujo objeto seria a totalidade da vida, biológica e social. Todavia, se na raiz da constituição do campo da saúde coletiva encontrava-se uma certa exclusão do biológico, até mesmo como estratégia de construção de identidade e legitimação, o que aqui se afirma como um novo ponto de inflexão é a recuperação, para o pensamento do objeto, do nível biológico, sem o qual torna-se impossivel pensar a vida e, por conseqüência, a própria idéia de saúde. Por isso, o II PSC imagina áreas e linhas de atuação para o campo. Uma primeira seria de natureza epistemológica, visando o aprimoramento de seu instrumental teórico-metodológico. Uma outra envolveria pesquisas orientadas para o estabelecimento de políticas nacionais em áreas estratégicas para o setor saúde, como, por exemplo, imunobiológicos, medicamentos e equipamentos biomédicos, entre outros. Finalmente, um terceiro nivel "corresponderia aos estudos e pesquisas voltados para a avaliação e aprimoramento das práticas de atenção à saúde". Traçando objetivos, metas e indicadores avaliativos, O II PSC consolida mais claramente previsões orçamentárias e, através de um Grupo de Assessoramento ampliado (pois passa a contar formalmente, além das agências financiadoras, presentes ao longo do processo, com o então INAMPS e representantes da comunidade científica), busca coordenar e compatibilizar demanda e oferta de recursos em função de um planejamento acordado.

O II Seminário de Avaliação do Programa de Saúde Coletiva realizou-se em dezembro de 1988. Um primeiro e fundamental destaque refere-se a uma certa imprecisão na definiçào e delimitação do campo e ao reconhecimento de que a Saúde Coletiva, sendo então uma área nova, não havia tido tempo, espaço e produção suficientes para sua completa configuração. Donde, uma certa multiplicidade de objetos, teorias, métodos e técnicas de investigação, o que, certamente, dificulta processos avaliatórios. Em primeiro lugar, da própria produção da área. Mas em segundo, e fundamentalmente, da eficácia da atividade de investigação científica quando se consideram seus produtos, referenciados ao que deveria ser uma política de ciência e tecnologia articulada a um projeto nacional que teve como núcleos aglutinadores a Constituição de 1988, a Reforma Sanitária e o Sistema Único de Saúde.

\section{Políticas Científicas e Tecnológicas em Saúde Coletiva $-\operatorname{anos} 90$}

O final da década de 80 significou, também, o fim do "modelo" de política científica vigente na Saúde Coletiva desde 1979. Desfez-se o Programa de Saúde Coletiva (PSC) em decorrência de uma significativa diminuição dos recursos disponíveis, tanto daqueles 
oriundos do FNDCT e geridos pela FINEP, quanto dos administrados pelo CNPq. Situação que em seus traços gerais perdura até os presentes dias, excetuando-se os mecanismos de distribuição de bolsas que foram relativamente preservados nesta crise. O sistema, sem dúvida, tem proporcionado importantes resultados quanto à formação de recursos humanos, também para a Saúde Coletiva, com reflexos positivos sobre o ensino e sobre os serviços de saúde. Ainda que a consolidação das pós-graduações represente um dos grandes sucessos da política de Ciência e Tecnologia brasileira, é evidente que a baixa disponibilidade de recursos para o financiamento de pesquisas repercute no impacto que as pósgraduações poderiam ter na formação de pesquisadores mais experimentados.

Constituindo-se em elemento importantíssimo para o esvaziamento das políticas de $\mathrm{C}$ \& T até então formuladas, a redução de recursos situa-se ao lado de outros fatores que para ele também contribuíram. Segundo Guimarães (1994a, p. 12): "A [razão] mais geral diz respeito às estreitas vinculações da política científica e tecnológica com a ação do Estado no âmbito de um projeto 'nacional'. Com a crise do Estado-Nação, vêm se ampliando as dificuldades para a reflexão e prática sobre $C \& T$. Sinergicamente, também concorre a posição dos países tardiamente industrializados no panorama da Terceira Revolução Industrial e da nova divisão do trabalho dela decorrente. A posição do Brasil, país periférico, de industrialização recente e desvinculado dos principais blocos econômicos existentes no momento, positivamente não anima o debate sobre as questões de $C \& T^{\prime \prime}$. Como elementos específicos que afetam a oferta, menciona o autor a existência de problemas nas políticas de coordenação, articulação, gestão e avaliação e, do lado da demanda, o (des)financiamento das universidades e a crise departamental.

Analisando os limites do desenvolvimento científico e tecnológico no Brasil, Ferraz (apud Marques, 1989, p. 19) diz haver: "um sério desajuste estrutural entre a oferta tecnológica e o quadro institucional existente no país, faltando capacitação técnica, gerencial e empresarial na burocracia pública e em muitos segmentos produtivos privados nacionais, bem como uma descoordenação entre agências públicas e inexistência de instrumentos de intervenção adequados para o fomento de C \& T no país".

Na área de Saúde Coletiva, como já foi apontado anteriormente, as políticas de C \& T vincularam-se fortemente ao movimento de sustentação do projeto da Reforma Sanitária. $\widehat{E}$ inegável que este movimento foi de fundamental importância no processo de redemocratização do país e na definição de direitos básico de cidadania na área da saúde (incorporados à Constituição de 1988), assim como na criação do Sistema Único de Saúde - SUS. Todavia, as conjunturas políticas, internas e externas, impediram a implantação efetiva de muitas dessas determinações legais e, tal como se verificou em outros países, instala-se uma certa percepção de crise na Saúde Coletiva: crise da teoria e/ou crise das práticas (OPS, 1992a)?

É como parte dessa conjuntura de relativa perplexidade que devem ser compreendidas as investigações que passam a ser propostas pela OPS, para diversos países da América Latina (inclusive o Brasil), visando analisar a pesquisa na área da saúde e melhor conhecer seus objetos, suas dinâmicas e resultados (OPS, 1992b, 1994, 1995b). "A singularidade da situação atual está dada pelo esgotamento deste modelo, em grande parte devido à diminuição da disponibilidade do seu apoio principal, os recursos públicos. O setor de $C \& T$, isolado e dependente do Estado, se transformou em um flanco bastante vulnerável para as políticas de 'ajuste', precisamente no momento em que a pesquisa em saúde requer um fortalecimento e reorganizaçāo para enfrentar novos e crescentes desafios, tais como manter-se em dia com a dinâmica cada vez mais acelerada do desenvolvimento científico-tecno- 
lógico (particularmente na área biomédica) e responder às demandas de conhecimento exigido pela complexidade crescente do quadro epidemiológico" (OPS, 1994, p. 394). Nesse senticlo, "estudos descritivos de perfis e tendências de investigação científica em um campo determinado ajudam a identificar problemas cardeais deste campo em momentos históricos precisos, abrindo caminho para estudos posteriores mais refinados que permitem aprofundar os determinantes das tendências observadas e predizer a direção do desenvolvimento neste campo, o que é de inegável importância para - processo de planejamento" (Pellegrini, 1992b, p. 15).

Os estudos sobre produção científica na área da saúde na década de 80 , que se valem de bases de dados como LILACS, MEDLINE e ISI, observam que no Brasil, para a área da saúde como um todo e da Saúde Coletiva em particular, houve um crescimento no número de publicações, ainda com baixa participação em revistas internacionais (Viacava et al., 1992; Guimarães \& Vianna, 1994; OPS, 1995b). Se para a América Latina, a participaçào brasileira no período apresenta uma tendência crescente, em relação à produção mundial a área da saúde mantém uma presença discreta, em torno de $1,5 \%$. Ressaltam os autores a dificuldade de interpretação dos dados registrados, principalmente quando se tenta utilizá-los como representativos da totalidade da produção científica. Dificuldade mais acentuada quando se trata da Saúde Coletiva dado que, freqüentemente, utiliza-se ela de outros veículos como instrumento de difusão dos resultados de suas pesquisas, tais como livros e relatórios técnicos, de difícil acesso quando se busca fazer análises da natureza da acima referida.

Em sintese, as avaliações das políticas de C \& T para a Saúde Coletiva na década de 80 , realizadas já no contexto do refluxo dos anos 90 , apontam para uma institucionalização de um sistema de pesquisa na área (cursos de pós-graduação, grupos de pesquisa consolidados cobrindo temáticas ampliadas), anco- rado fundamentalmente nos meio acadêmico. Concentra-se de uma forma muito importante na região sudeste, observando-se uma baixa produtividade quando medida pelo número de publicações e comparada a padrôes internacionais. É uma área ainda pouco resistente a crises conjunturais, dado que se vale de uma variedade restrita de fontes de financiamento e com uma lenta renovação de seus quadros de pesquisadores. Pode-se considerar, no entanto e clesse ponto de vista, que as políticas científicas para a área foram relativamente bem sucedidas, ainda que não tenham alcançado as metas inicialmente estabelecidas.

No que diz respeito às políticas dirigidas ao desenvolvimento tecnológico, a atividade realizada no interior da Saúde Coletiva revelou-se bastante restrita e sujeita a descontinuidades. A Organização Panamericana de Saúde propôs e apoiou investigações na área de "avaliação e desenvolvimento tecnológico em saúde" (OPS, 1985; 1995a), em que foram desenvolvidos temas relativos às tecnologias de produtos e sua incorporação pelos sistemas de atenção à saúde. O resultado revelouse muito aquém do esperado devido ao baixo impacto da iniciativa tanto na área da Saúde Coletiva como fora dela. No que se refere à transferência de conhecimentos científicos que resultem em inovações e produtos industrializáveis, tais como medicamentos, equipamentos e imunobiológicos, a reduzida articulaçào da Saúde Coletiva com as áreas de pesquisa básica (biologia, física e química), assim como à pesquisa aplicada (engenharia) e seu quase total desconhecimento do setor industrial levaram a que sua participação (enquanto área do conhecimento) nos poucos projetos bem sucedidos fosse quase marginal. De toda forma, é possivel identificar um determinado esforço de articulaçào, como se vê, por exemplo, no documento elaborado pelo Grupo Técnico de Assessoramento em C \& T da Comissão Nacional de Reforma Sanitária (CNRS, 1987). 
Em relação a "tecnologias de processo", pode-se dizer que a Saúde Coletiva teve ativa participação na elaboração de propostas de planejamento, administração, programação e gestão, tendo em vista a Reforma Sanitária e a implantação do SUS. A avaliação de tal atividade reveste-se de enormes dificuldades dado que, e principalmente, a reformulação do sistema de saúde tem se revelado muito mais problemática do que se pensava, expressando uma dinâmica complexa que, por vezes, mascara a eventual incorporação efetiva de processos inovadores.

De toda forma, mudanças se anunciavam necessárias. Os primeiros anos da década de 90 mostraram uma ausência quase total de qualquer tipo de atividade prospectiva. No fundamental, tentava-se sobreviver ao "furacão Collor". Desde então, foram organizados alguns grandes eventos, com recortes específicos, e que tomaram a política de $\mathrm{C} \& \mathrm{~T}$ como temática central. A se ressaltar, portanto, a ausência de uma atividade estruturada, articulada e de natureza contínua que trabalhe esta questão, e que diga respeito não só à Saúde Coletiva mas, também, ao setor saúde como um todo. Alguns desses eventos devem ser lembrados.

Em 1993, a Fundação Oswaldo Cruz FIOCRUZ - realiza seu II Congresso Interno, tendo por tema "Ciência e Saúde - Compromisso Social da FIOCRUZ". No texto do seminário preparatório "Ciência, Tecnologia e Saúde: Funções Públicas face às Transformações Sociais" afirma-se que: "o que se impõe na atualidade é a substituição da ausência de uma seletividade estrutural dada pela definição de uma arbitrariedade politicamente construída. Em outros termos, teremos que definir prioridades, traçar estratégias, criar mecanismos de planejamento e avaliação contínuos." (FIOCRUZ, 1993a, p. 9). Sendo assim, "as opções de desenvolvimento científico e metodológico em saúde devem ter a sensibilidade de reconhecer a dinâmica da realidade social e sanitária nacicinal, identificar os pontos críticos e as estratégias a curto, médio e longo prazo. Da mesma forma que não devem desconhecer que - processo de desenvolvimento científico não pode estar alheio às relações tanto com a comunidade internacional quanto com o setor produtivo." (idem, p. 11). Em relação às "propostas para discussão", considera-se que, para a Instituição, são parâmetros de priorização de pesquisa "o quadro epidemiológico, a vocação institucional, as demandas sociais, a excelência científica e o acompanhamento do desenvolvimento científico institucional", constituindo-se em critérios de relevância "impacto na morbidade, impacto ambiental, produção e desenvolvimento tecnológico, circulação e difusão da informação e integração multidisciplinar e intra/interinstitucional." (FIOCRUZ, 1993b).

Em junho de 1994, a Academia Brasileira de Ciências, dando continuidade aos "Encontros Setoriais: Contribuições de Ciência e Tecnologia para a Área Social", enfocou a questão da saúde, promovendo um encontro das comunidades científica e tecnológica e, também, com a comunidade empresarial, do qual resultou a proposição de macrodiretrizes para uma política de C \& T em saúde. A partir da identificação de "entradas" ou "conceitos organizadores" para o agrupamento das finalidades das práticas de $\mathrm{P} \& \mathrm{D}$ em saúde (Novaes, Szklo \& Lafetá, 1994), foram definidos quatro campos "fim" e um campo "meio": pesquisa básica ou fundamental; $\mathrm{C} \& \mathrm{~T}$ aplicadas a objetivos econômicos; C \& T aplicadas a objetivos estratégicos; C \& T aplicadas ao planejamento, organização e gerenciamento de sistemas de saúde e, finalmente, Infraestrutura de C \& T. Esta categorização permitiria não só a identificação da especificidade das áreas do conhecimento e de suas práticas, e das instituições mais adequadas ao seu desenvolvimento, mas também a visualização das articulações necessárias à realização de objetivos sociais específicos.

As seguintes macrodiretrizes foram ali formuladas: 
I - Ciências básicas ou Fundamentais: a pesquisa básica na área de saúde deve respeitar a dinâmica própria da Ciência, conciliando-se com a adoção de políticas temáticas para esta área.

II - C E T aplicadas a Objetivos Econômicos:

a) Reorganização empresarial visando reestruturar segmentos do parque industrial de produtos (insumos, equipamentos e serviços) para a saúde, de forma a aumentar a capacidade de inovação;

b) Criação de mecanismos que assegurem a qualidade dos produtos (insumos $\mathrm{e}$ equipamentos) e serviços de saúde no país;

c) Criação de condições empresariais para o desenvolvimento da indústria de química farmacêutica no país, e

d) Criação de condições empresariais para o desenvolvimento da moderna biotecnologia direcionada para a saúde.

III - C E T aplicadas a Objetivos Estraté gicos:

a) Criar infra-estrutura técnico-científica capacitada a identificar áreas consideradas estratégicas para o aprimoramento das condições de saúde através das atividades de C \& T;

b) Promover o processo de aprimoramento da intervenção estatal na implementação de $\mathrm{P}$ \& D em insumos considerados estratégicos, e

c) Fortalecer a atividade regulatória do Estado.

IV - C E T aplicadas ao Planejamento, Organização e Gerenciamento de Sistemas e Serviços de Sauide: desenvolvimento da C \& T necessárias à superação de lacunas de conhecimento e tecnologias na implantação e desenvolvimento do SUS e, finalmente,

V - Infra-estrutura de $C$ E $T$ : identificar áreas relativas à infra-estrutura a serem apoiadas na otimização da C \& T em saúde e desenvolver ações necessárias ao seu pleno funcionamento (ABC, 1994).

Em uma seqüência cronológica, a Coordenação Geral de Desenvolvimento Científico e Tecnológico do Ministério da Saúde organizou e realizou, em outubro de 1994, a I Conferência Nacional de Ciência e Tecnologia em Saúde, como coroamento de conferências estaduais. Apoiados em documentos especialmente preparados para a ocasião, assim como em apresentações e debates, os participantes (representando diversos segmentos envolvidos com a questão) elaboraram um documento que deveria definir uma política de $C \&$ T em saúde, como componente da própria Política Nacional de Saúde (Ministério da Saúde, 1994).

São ali analisadas as relações entre saúde, desenvolvimento e eqüidade social, os novos paradigmas científicos e tecnológicos e o papel do Estado, assim como a participação fundamental da pesquisa e do desenvolvimento da saúde na construção da eqüidade. São ainda mencionadas propostas de organismos internacionais como a Organização Mundial da Saúde - OMS e Banco Mundial, que enfatizam a contribuição que a $C \& \mathrm{~T}$ podem oferecer à melhoria das condições de saúde dos países mais pobres, defendendo o estabelecimento de metas que priorizem respostas específicas por partes destes mesmos países ("Health Research for Development" e "Essential National Health Research"). Após um diagnóstico do Sistema Nacional de Ciência e Tecnologia, e de sua interação com o Sistema Nacional de Saúde (traduzido pela identificação das dificuldades que o Ministério da Saúde tem encontrado para uma adequada articulação dos mesmos), são apontadas formas alternativas para definições de prioridades de C \& T em Saúde. Dependeriam elas, basicamente, do desenvolvimento de condições para uma efetiva incorporação de práticas mais integradoras, ágeis e melhor fundamentadas científica e tecnicamente. Em conclusão, propõe o documento a criação, no 
Ministério da Saúde, de uma Secretaria Executiva de $C \& \mathrm{~T}$, assim como a atribuição a uma forma ampliada da Comissão Intersetorial de C \& T em Saúde - CICT - , do Conselho Nacional de Saúde, a tarefa de formular, propor e acompanhar a Política Nacional de C \& T em Saúde (Ministério da Saúde, Ministério da Educação e do Desporto, Ministério da Ciência e da Tecnologia, 1994). Seguindo o mesmo impulso, a ABRASCO cria sua própria Comissão de $\mathrm{C} \& \mathrm{~T}$ em Saúde, como reflexo de esperanças renovadas.

Passados dois anos, verifica-se que as propostas de reorganização administrativa que levariam a um sistema articulado de política de $C$ \& $T$ em saúde, praticamente, não se implantaram, os recursos para pesquisa continuam escassos e a Comissão de $\mathrm{C} \& \mathrm{~T}$ da ABRASCO não saiu do papel. No entanto, e felizmente, ainda há vida. Os grupos de pesquisa continuam em atividade e procuram diversificar suas fontes de financiamento; as tradicionais instituições financiadoras buscam criar mecanismos que as tornem mais ágeis e objetivas (a CAPES merece uma especial referência), ampliaram-se os intercâmbios interinstitucionais e internacionais, e promovem-se congressos também para áreas específicas do campo da Saúde Coletiva, que mostram uma grande diversidade de temas e abordagens.

Assim, no presente momento, ainda que o exercício da política (politics) esteja sempre

\section{Referências bibliográficas}

ACADEMIA BRASILEIRA DE CIÊNCIAS (1994) Relatório Final. Encontros Setoriais: Contribuições de Ciência e Tecnologia para a Área Social - Saúde. Rio de Janeiro: Academia Brasileira de Ciências.

BALTAR, J. M. (1993) - Mudança tecnológica e desenvolvimento. Brasilia, mimeo.

CASSEN, B. (1991) - Pour un pluralisme linguistique. In: Witkowski, N. (org.) - L'Etat des Sciences et des Techniques. Paris: Éditions La Découverte. presente, e continue fundamental, e a sua tradução em definições de políticas (policies) explícitas e formalizadas não deixe de ser importante, enquanto elemento racionalizador e aglutinador, estas somente poderão se constituir em diretrizes com alguma efetividade se souberem captar e potencializar a diversidade, heterogeneidade e complexidade da produção de conhecimentos e práticas, e da própria vida social, resistindo à tentação demiúrgica de recriar o mundo somente através dos desejos.

O diagnóstico geral quanto aos problemas a serem enfrentados já existe e, no novo contexto dos anos 90, o principal desafio para que uma política de $C \& \mathrm{~T}$ deixe de ser um exercício virtual e seja capaz de se consolidar como uma política pública, com legitimação social, é conseguir mobilizar e envolver a diversidade de atores presentes na produção, disseminação e utilização dos conhecimentos e das tecnologias. Os atores sociais, em qualquer atividade, não estão dados a priori, visto que vão sendo incorporados no decorrer da sua dinâmica. Para a C \& $\mathrm{T}$ em Saúde, além de novos atores, fazem-se necessárias mudanças nas práticas dos atores tradicionais, como o Estado, os pesquisadores, as associações científicas, os produtores de serviços e insumos, e os profissionais de saúde, para a construção de novas relações de poder, formas de convivência e dinâmicas de trabalho.

CHESNAIS, F. (1991) - L'inéluctable internationalisation de la recherche et de la technologie. In: Witkowski, N. (org.) - L'Etat des Sciences et des Techniques. Paris: Éditions La Découverte.

CNRS - Comissão Nacional de Reforma Sanitária (1987) - A incorporação da Ciência e da tecnologia pelo setor saúde. Relatório Técnico. Brasília, mimeo.

FINEP (1987) - Programa de Saíde Coletiva (1987- 1989). Rio de Janeiro: FINEP 
FINEP/CNPq (1986) - Reunião de Avaliação do Programa de Saúde Coletiva FINEP/CNPq. Estudos de Saride Coletiva n. 4. Rio de Janeiro: ABRASCO, p. 69-90.

FIOCRUZ (1993a) - Ciência, Tecnologia e Saúde: Funçōes Públicas face às Transformaçōes Sociais. Ciência e Saúde. Compromisso social da FIOCRUZ. II Congresso Interno da FIOCRUZ, Rio de Janeiro, mimeo.

FIOCRUZ (1993b) - Propostas para Discussão. Ciência e Saúde. Compromisso social da FIOCRUZ. II Congresso Interno da FIOCRUZ, Rio de Janeiro, mimeo.

GAILlARD, J. (1991) - La science du tiers monde entre deux mondes. In: Witkowski, N. (org.) - L'Etat des Sciences et des Techniques. Paris: Éditions La Découverte.

GUIMARĀES, R.F.N. \& VIANNA, C.M.M. (1994) Ciência e Tecnologia em Saúde. Tendências Mundiais. Diagnóstico Global e Estado da Arte no Brasil. Anais da I Conferência Nacional de Ciência e Tecnologia em Saúde. Brasilia: Ministério da Saúde, Ministério da Educação e do Desporto, Ministério da Ciência e Tecnologia, p. 115-236.

GUIMARĀES, R.F.N. (1994) - Avaliação e fomento de C E T no Brasil: propostas para os anos 90 . Brasília: MCT/CNPq.

HATZICHRONOGLOU, T. (1991) - Budgets, financements, acteurs de la R-D...une comparaison internationale. In: Witkowski, N. (org.) - L'Etat des Sciences et des Techniques. Paris: Éditions La Découverte.

MARQUES, M.B. (1989) - Limites ao desenvolvimento científico e tecnológico em saúde no Brasil. Série Política de Saíde n. 9. Rio de Janeiro: FIOCRUZ.

MCT (1985) - Ciência e tecnologia na Nova República: análises e perspectivạs. Brasîlia, mimeo.

MCT/FINEP/CNPq (1985) - Ciência e tecnologia numa sociedade democrática. Brasília: MCT.

MS/MED/MCT (1994) - Relatório Final. Anais da I Conferência Nacional de Ciência e Tecnologia em Satide. Brasília: MS.

NOVAES, M.; SZKLO, F. \& LAFETÁ, R. (1994) Termos de referência para a construçào de um diagnóstico da ciência e tecnologia em saúde no Brasil boje: Parâmetros para a seleçào de conceitos organizadores - primeiras reflexöes. Encontros Setoriais: Contribuições de Ciência e Tecnologia para Área Social - Saúde. Rio de Janeiro: Academia Brasileira de Ciências.

OECD (1991) - Choosing Priorities in Science and Technology. Paris: OECD.

OECD (1992) - Science and Technology Policy. Revieu and Outlook. 1991. Paris: OECD.

OPS (1985) - Conferência Interamericana sobre avaliação tecnológica em saúde. Anais. Brasília: CNPq/OPS.

OPS (1992a) - La crisis de la salud pública: reflexiones para el debate. Publicación científica n. 540. Washington: OPS.

OPS (1992b) - La investigación en salud en América Latina. Publicación Científica n. 543. Washington: OPS.

OPS (1994) - Las Condiciones de Salud en las Americas. Publicación Científica n. 549. Washington: OPS.

OPS (1995a) - Desarrollo Tecnológico en Salud. Trabajos Presentados: Primera Parte. Seminário Internacional, Brasilia, 1994. Washington: OPS.

OPS (1995b) - Producción científica en salud en América Latina 1973 - 1992. Washington, mimeo.

PELLEGRINI, A. (1992) - Introducción. In: La investigación en salud en la América Latina. Publicación Científica n. 543. Washington: OPS.

PELLEGRINI, A.; NICOLETTI, L. et al. (1986) Pesquisa em Saúde Coletiva. Estudos de Saúde Coletiva 4: 41-52.

ROSENBERG, N. (1994) - How the Developed Countries Became Rich. Daedalus, 123(4):127-140.

STENGERS, I. (1993) - L'invention des sciences modernes. Paris: Éditions La Découverte.

SZKLO, F. (1988) - Uma avaliação crítica da versão preliminar do relatório final do Seminário "Avaliação e Perspectivas do Programa de Saúde Coletiva", Caxambu Setembro, 1988. Rio de Janeiro, mimeo.

VIACAVA, F. et al. (1992) - La investigación en salud en el Brasil. In: La investigación de salud en América Latina. Publicación Científica n. 543. Washington: OPS. 